\title{
Iniciando el catálogo del pintor Antonio Hidalgo: las Ánimas del Purgatorio (1688)
}

\section{Antonio Romero Dorado ${ }^{1}$}

CIHAA, Universidad de Sevilla

Resumen: Este trabajo da a conocer una obra firmada en 1688 por el pintor Antonio Hidalgo, perteneciente a la escuela sevillana y activo entre 1664 y 1689 . Se trata de su única obra identificada

Palabras clave: Antonio Hidalgo, pintura barroca en España, escuela sevillana, Conil de la Frontera

\begin{abstract}
This paper discloses a work signed in 1688 by the painter Antonio Hidalgo, an artist from the Seville school of painting who was active between 1664 and 1689 . It is his first identified painting
\end{abstract}

Key Words: Antonio Hidalgo, baroque painting in Spain, Seville school, Conil de la Frontera

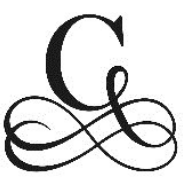

on este breve trabajo queremos dar a conocer una pintura fechada en 1688 y firmada por el pintor español Antonio Hidalgo, perteneciente a la escuela sevillana y activo entre 1664 y $1689 .^{2}$ Su relevancia radica en que se trata de la primera pintura que podemos asignar con certeza a este artista, que hasta ahora solo se conocía a través de los documentos. La obra en cuestión se encuentra en la villa de Conil de la Frontera, en Andalucía. Se conserva en la actual Iglesia parroquial de Santa Catalina, que es la antigua iglesia del Convento de la Victoria, de padres mínimos de San Francisco de Paula. Este templo también es conocido como Iglesia de las Virtudes, por albergar la imagen de la Virgen de dicha

\footnotetext{
1 https://orcid.org/0000-0002-4979-0491

2 Enrique Valdivieso, Historia de la pintura sevillana: siglos XIII al XX (Sevilla: Guadalquivir Ediciones, 2002), p. 286. Enrique Valdivieso, Pintura barroca sevillana (Sevilla: Guadalquivir Ediciones, 2003), p. 469.
}

(C) 2017 Philostrato. Revista de Historia y Arte 
advocación que es patrona del municipio. ${ }^{3}$ La pintura que presentamos se encuentra colgada sobre la puerta de acceso a la sacristía, en un espacio adyacente a la iglesia donde se ubica una gran escalera. Se trata de una pintura de altar de aproximadamente $220 \times 150 \mathrm{~cm}$., realizada al óleo sobre lienzo. En ella se representa, en la parte inferior, las Ánimas del Purgatorio; en el centro, el arcángel San Miguel flanqueado por dos papas arrodillados y respaldados por San Pablo y Santa Catalina; mientras que en la zona superior hay una visión de Cristo en la Gloria, representado como juez, con la Virgen María arrodillada a su derecha y una cohorte de santos y de ángeles músicos (fig. 1).

Podemos afirmar que se trata de una obra de Antonio Hidalgo porque en la pintura hay una hoja pintada, en la que aparece la siguiente leyenda: "ESTA PINTURA SE HIZO SIENDO VICARIO DE ESTA SANTA IGLESIA EL LICENCIADO FRANCISCO DE MENDOZA $Y$ HERMANOS MAYORES EL LICENCIADO JUAN DE ARROYO Y D. BARTOLOMÉ BUSTAMANTE DE ESTA HERMANDAD AÑO DEL SEÑOR DE 1688. ANTONIO HIDALGO FECIT." (fig. 2). Como podemos observar, estas palabras nos informan del autor, de la fecha y de la institución comitente, que parece ser la Hermandad de las Ánimas de Conil, que por esos años suponemos radicada en la antigua parroquial de Santa Catalina, de ahí que en la pintura aparezca la santa de Alejandría. Al parecer, por aquellos años, esta cofradía era la más boyante de la diócesis gaditana, con una renta anual de 2300 reales, cantidad que sin embargo no dejaba de ser bastante exigua. ${ }^{4}$

Resulta especialmente relevante que el año de ejecución sea 1688 pues, dentro de lo que sabemos de la vida del artista, la pintura de Conil sería una obra de madurez y, por lo tanto, nos da una idea de cuál fue el alcance del arte de Hidalgo. Sin embargo, la obra presenta un pésimo estado de conservación, lo que compromete bastante la emisión de un juicio fiable. Asimismo, el asunto de las Ánimas del Purgatorio, aunque con numerosísimas variantes, se trata de una iconografía bastante codificada y establecida, que no nos facilita valorar la inventiva del autor y su capacidad compositiva. Lo cierto es que en la obra se aprecia una gran simetría axial y cierta frontalidad en las figuras, que están representadas en pocos planos de profundidad, apenas relacionados entre sí. En cuanto a la conservación, se observa una clara degradación del soporte en la parte inferior y se distingue con claridad una quemadura sobre la zona del papel que contiene la leyenda aludida. Asimismo el aspecto general de la obra es amarillento y todos los colores están apagados por la oxidación y el pasmado del barniz, adivinándose pérdidas parciales de la capa pictórica. Además, la ubicación de la pintura dificulta su apreciación y no le beneficia el hecho de estar en un espacio arquitectónico parcialmente abierto a la intemperie.

\footnotetext{
${ }^{3}$ Lorenzo Alonso de la Sierra, Juan Alonso de la Sierra, Pablo Pomar Rodil, y Miguel Angel Mariscal, Guía artística de Cádiz y su provincia: Bahía de Cádiz, Costa Noroeste, La Janda, Campo de Gibraltar y Sierra de Cádiz, (Sevilla: Fundación José Manuel Lara, 2005), tomo 2, pp. 233-237.

${ }^{4}$ Arturo Morgado García, La Diócesis de Cádiz: De Trento a la Desamortización (Cádiz: Universidad de Cádiz, 2008), p. 377.
} 


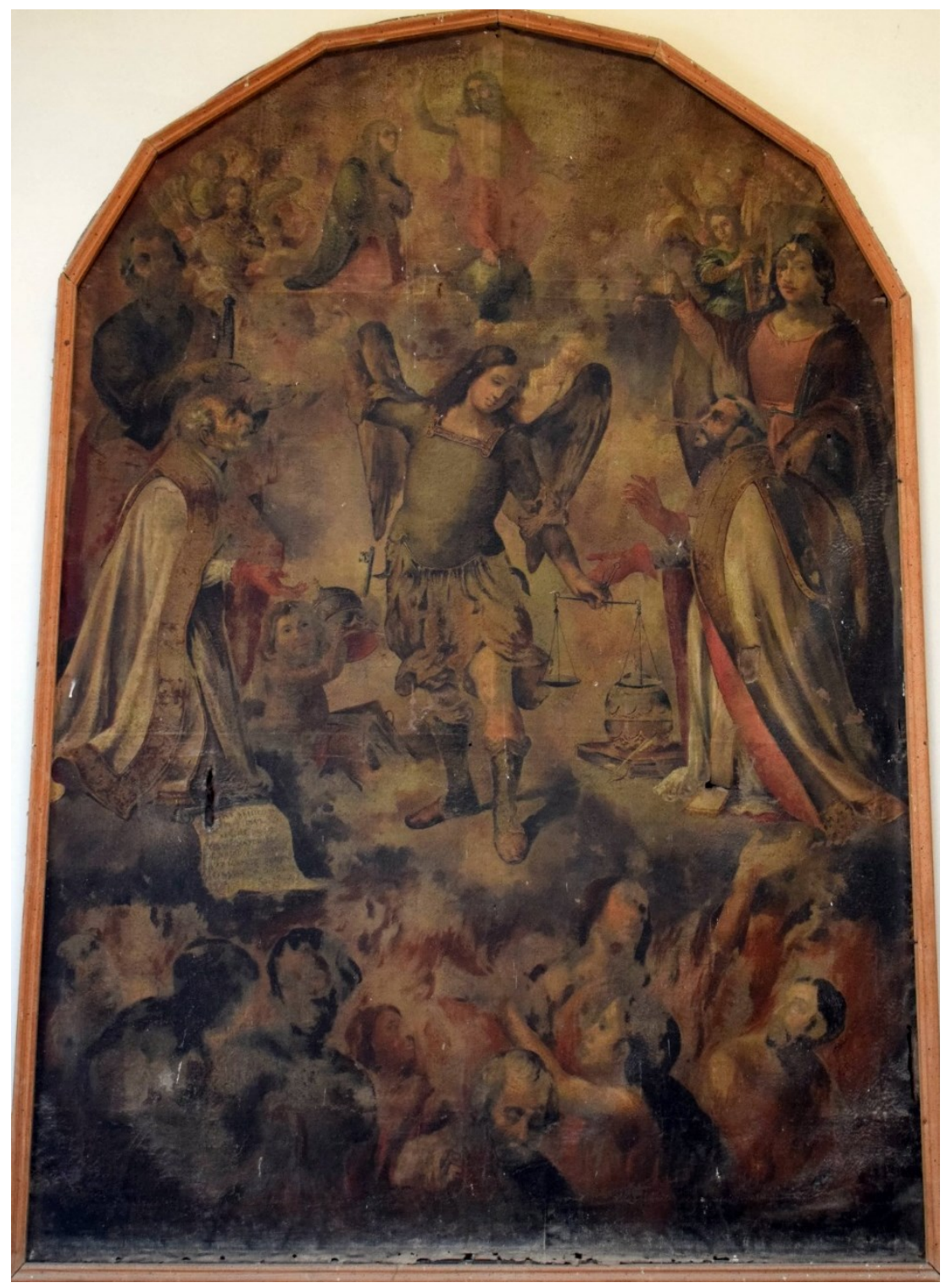

Fig. 1. Antonio Hidalgo, Las Ánimas del Purgatorio, 1688, iglesia parroquial de Santa Catalina, Conil de la Frontera (Cádiz) (Cfoto del autor)

Con todo, no son muchas las conclusiones que podemos extraer, si bien podría afirmarse que Hidalgo parece un pintor correcto aunque discreto. Desconocemos dónde nació pero se le puede suponer un origen hispalense, en sentido amplio. En 1664 compareció en Sevilla como testigo en la redacción del testamento de Bernabé de Ayala, junto a quien fue miembro, entre 1668 y 1674, de la Academia del Arte de la Pintura, fundada en la ciudad por Murillo y Herrera el Mozo. En dicha institución contribuyó con 8 reales en 1671 para el funeral del I conde de los Arenales, ${ }^{5}$ D. Juan Fernández de Henestrosa, protector de la Academia, de la que Hidalgo figura como notario en 1674. Posteriormente, se instaló en Cádiz, donde el 27 de marzo de 1680, junto a otros diecinueve pintores de la ciudad, demandó que la pintura fuera exonerada de impuestos municipales. En Cádiz, aparece en

${ }^{5}$ Ramón Corzo Sánchez, La Academia del Arte de la Pintura de Sevilla, 1660-1674 (Sevilla: Instituto de Academias de Andalucía, 2009), p. 77. 
1689 junto a Ayala como albacea del pintor Miguel Legot, hijo de Pablo. ${ }^{6}$ Desde allí debió realizar encargos para instituciones religiosas de la diócesis gaditana, como el lienzo de las Ánimas de Conil, y es probable que Hidalgo, como otros pintores de formación sevillana trasladados a Cádiz, falleciera en esta última ciudad.

Hasta el momento no se había identificado ninguna obra de Antonio Hidalgo, aunque ya se tenía noticia de dos floreros suyos que formaban parte de una colección sevillana y que, al parecer, eran comparables a los de Juan de Arellano y Pedro de Camprobín. ${ }^{7}$ Por su parte, la Inmaculada Concepción perteneciente al Museo del Prado y firmada "HIDALGO", ${ }^{8}$ le fue atribuida pero actualmente se asigna a José García Hidalgo (1645-1717). En efecto, dicha Inmaculada no se corresponde con lo que vemos en la pintura de las Ánimas de Conil; una obra que merece ser restaurada y reubicada, entre otros motivos, para garantizar su integridad y por ser la única muestra conocida de la pintura de Antonio Hidalgo.

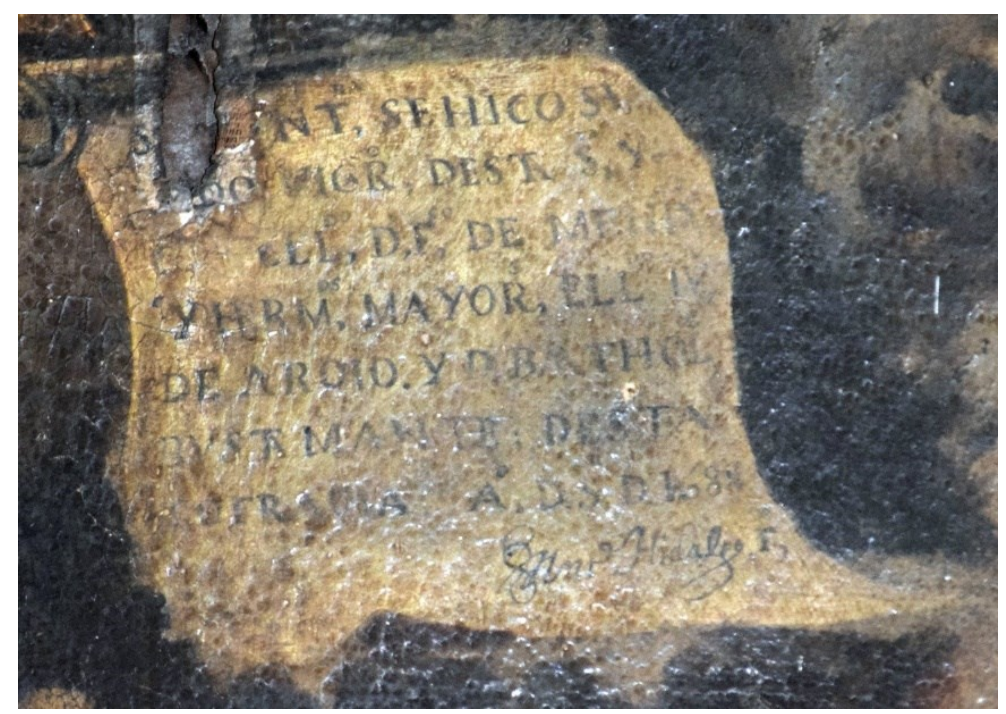

Fig. 2. Detalle de la leyenda de Las Ánimas del Purgatorio, detalle de la firma de Antonio Hidalgo, iglesia parroquial de Santa Catalina, Conil de la Frontera (Cádiz) (foto del autor)

\footnotetext{
${ }^{6}$ Eduardo Lamas Delgado, "Le peintre Bernabé de Ayala et autres petits maîtres entre Séville et Cadix", Annales d'Histoire de l'art et d'archéologie, no 36, (2014), pp. 71-94; Eduardo Lamas Delgado, "El pintor Miguel Legot (Sevilla, c. 1627-Cádiz, 1695)", El Rincón malillo, no 5, (2015), pp. 47-52.

7 Conde de Viñaza, Adiciones al diccionario histórico de Ceán Bermúdez. Vol. II, (Madrid: Tipografía de los Huérfanos, 1889), p. 283.

8 Número de inventario: P03207. Óleo sobre lienzo, $205 \times 155 \mathrm{~cm}$.
} 
Bibliografía:

Alonso 2005: Lorenzo Alonso de la Sierra, Juan Alonso de la sierra, Pablo Pomar Rodil y Miguel Angel Mariscal, Guía artística de Cádiz y su provincia: Bahía de Cádiz, Costa Noroeste, La Janda, Campo de Gibraltar y Sierra de Cádiz, (Sevilla: Fundación José Manuel Lara, 2005), tomo 2

Conde de Viñaza, 1889: Conde de Viñaza, Adiciones al diccionario histórico de Ceán Bermúdez. Vol. II, (Madrid, Tipografía de los Huérfanos, 1889)

Corzo, 2009: Ramón Corzo Sánchez, La Academia del Arte de la Pintura de Sevilla, 1660-1674, (Sevilla: Instituto de Academias de Andalucía, 2009)

Lamas, 2014: Eduardo Lamas Delgado, "Le peintre Bernabé de Ayala et autres petits maîtres entre Séville et Cadix", Annales d'Histoire de l'art et d'archéologie, no 36, (2014), pp. 71-94.

Lamas, 2015: Eduardo Lamas Delgado, "El pintor Miguel Legot (Sevilla, c. 1627-Cádiz, 1695)", El Rincón malillo, no 5, (2015), pp. 47-52.

Morgado, 2008: Arturo Morgado García, La Diócesis de Cádiz: De Trento a la Desamortización (Cádiz: Universidad de Cádiz, 2008)

Valdivieso, 2002: Enrique Valdivieso, Historia de la pintura sevillana: siglos XIII al XX (Sevilla: Guadalquivir Ediciones, 2002)

Valdivieso, 2003: Enrique Valdivieso, Pintura barroca sevillana (Sevilla: Guadalquivir Ediciones, 2003)

Recibido: $28 / 08 / 2017$

Aceptado: $30 / 10 / 2017$ 